\title{
PASADO, PRESENTE Y FUTURO DE LA JUSTICIA TRANSICIONAL EN EL SISTEMA INTERAMERICANO DE DERECHOS HUMANOS*
}

\author{
PAST, PRESENT AND FUTURE OF \\ TRANSITIONAL JUSTICE IN THE INTER- \\ AMERICAN HUMAN RIGHTS SYSTEM
}

JuANA InÉs ACOSTA-LÓPEZ**

Cindy EsPitia-MurciA ${ }^{* * *}$

Fecha de recepción: 15 de mayo de 2017

Fecha de aceptación: 2 de junio de 2017 Disponibilidad en linea: 30 de junio de 2017

\begin{abstract}
PARA CITAR Este ARTículo / To CITE This ARTICle
Acosta-López, Juana Inés y Espitia-Murcia, Cindy, Pasado, presente y futuro de la justicia transicional en el sistema interamericano de derechos humanos, 30 International Law, Revista Colombiana de Derecho Internacional, 9-40 (2017). https://doi.org/10.11144/ Javeriana.il 15-30.ppfj

doi:10.11144/Javeriana.i115-30.ppfj
\end{abstract}

\footnotetext{
* Artículo elaborado en el marco del proyecto de investigación de interacciones entre el Derecho Internacional y el Derecho Interno del Grupo de Derecho Internacional de la Universidad de La Sabana. Contacto: juanaacosta20@gmail.com

** Comunicadora social y periodista y estudiante de derecho de la Universidad de La Sabana.

*** Estudiante coordinadora del semillero de Justicia Transicional de la Universidad de La Sabana.Contacto: cindyesmu@gmail.com
} 


\section{RESUMEN}

No existen dudas de que el papel de la Corte Interamericana de Derechos Humanos(Corte IDH) será fundamental para la sostenibilidad de la pazen Colombia. Las decisiones de este tribunal relacionadas con los mecanismos judiciales y extrajudiciales de justicia transicional y la convencionalidad del texto del Acuerdo de Paz y de las normas y políticas proferidas para su implementación, ya están teniendo y tendrán un efecto fundamental en el rumbo que tomará el país en los próximos años. En este sentido, resulta de vital importancia revisitar la jurisprudencia del Tribunal Internacional desde una perspectiva crítica y propositiva, con el fin de analizar si las reglas establecidas por la Corte en el pasado (en su gran mayoría tránsito de dictaduras a democracia) han sido modificadas o contextualizadas en la jurisprudencia aún incipiente del presente (tránsitos de conflicto armado a la paz y paz negociada) y plantear los retos y desafíos de la jurisprudencia del futuro, especialmente para el caso de Colombia. Este artículo pretende aportar a este análisis, a partir del estudio, tanto de los casos que ya han sido decididos por el Tribunal Internacional, como de aquellos que están en trámite en esta sede judicial.

Palabras clave: justicia transicional; Corte Interamericana de Derechos Humanos; verdad; justicia; reparación 
The role of the Inter-American Court of Human Rights to the sustainability of Colombia's peace is uncontestable. The decisions of this regional Tribunal, related to judicial and extrajudicial mechanisms of transitional justice and to the compatibility of the Peace Agreement and the norms and policies issued to its implementation with the American Convention, are already having and will have a fundamental effect in the forthcoming years. Accordingly, it is necessary to revisit the International Tribunal's case law from a critical and proposal perspective, in order to analyze if the rules established by the Court in the past (most of them, transitions from dictatorships to democracy), have been modified or contextualized in the still incipient case law of the present (transitions from armed conflicts to negotiated peace), and to raise the challenges of the case law of the future, considering in particular the case of Colombia. This article aims to contribute to this analysis, based on the study-both of the cases that have already been decided by the International Tribunal-, as well as those that are in process in this judicial seat.

Keywords: Transitional Justice; Inter-American Court of Human Rights; Truth; Justice; Reparation

SUMARIO

INTRODUCCIÓN. I. PASADO, PRESENTE Y FUTURO DEL DERECHO A LA VERDAD. II. PASADO, PRESENTE Y FUTURO DEL DERECHO A LA JUSTICIA. A. En relación con las amnistías. B. ¿Investigar, juzgar y sancionar a todos los responsables? III. PASADO, PRESENTE Y FUTURO DEL DERECHO A LA REPARACIÓN. CONCLUSIONES 
INTRODUCCIÓN

La mayoría de las discusiones y debates sobre justicia transicional se refiere a los estándares internacionales en relación con el derecho a la justicia. ${ }^{1}$ Poco, en cambio, se habla de los presupuestos fundamentales y básicos con respecto al derecho a la verdad y la reparación.

Para el análisis de una estrategia de justicia transicional como la propuesta para Colombia, en la que el principio de integrali$d a d^{2}$ constituye uno de los principales fundamentos del modelo adoptado en el Acuerdo de Paz, es necesario analizar la evolución de la jurisprudencia en relación con los tres derechos. En tal sentido, no resulta adecuado revisar el componente de justicia como si fuera independiente de los mecanismos extrajudiciales relacionados con la satisfacción de los derechos a la verdad y a la reparación.

Por supuesto, tampoco tendría sentido analizarlos sin considerar las garantías de no repetición que, sin desconocer su importante valor - compartimos con otros autores-, son independientes de las medidas de reparación integral. ${ }^{3}$ Sin embargo, para efectos de este artículo, se abordará el derecho a la verdad,

1 Luis Gutiérrez, La obligación internacional de investigar, juzgar y sancionar graves violaciones a los derechos humanos en contextos de justicia transicional, Estudios SocioJurídicos, 16, 23-60 (2014); Olger Espinosa, Acerca del "control de convencionalidad" por parte de los operadores de justicia (nacionales e internacionales) en situaciones de justicia transicional, Revista IIDH, 25, 215-271 (2012); Tricia Olsen, Leigh Payne \& Andrew Reiter, The Justice Balance: When Transitional Justice Improves Human Rights And Democracy, Human Rights Quarterly, 32, 980-1007 (2010); Patricia Lundy \& Mark McGovern, Whose Justice? Rethinking Transitional Justice from the bottom up, Journal of Law and Society, 35, 265-292 (2008); Louise Mallinder, Amnesty, human rights and political transitions: bridging the peace and justice divide, 21, 218-232 (1 Ed., Bloomsbury Publishing, Portland, 2008); Camila de Gamboa Tapias, Justicia transicional: dilemas y remedios para lidiar con el pasado, Estud. Socio-Juríd, 7, 21-40 (2005).

2 El Sistema Integral de verdad, justicia y reparación contemplado en el Acuerdo Final está conformado por: 1) la Comisión para el Esclarecimiento de la verdad, la convivencia y la no repetición; 2) la Unidad especial para la búsqueda de personas dadas por desaparecidas en el contexto y en razón del conflicto; 3) la Jurisdicción Especial para la Paz y 4) los mecanismo de reparación integral. Acuerdo final para la terminación del conflicto y la construcción de una paz estable y duradera. 24 de noviembre de 2016. Punto 5. Sistema Integral de Verdad, Justicia, Reparación y No Repetición.

3 María Carmelina Londoño, Las garantías de no repetición en la jurisprudencia interamericana: derecho internacional y cambios estructurales del Estado, I, 19-38 (1 Ed., Tirant Lo Blanch, México, 2014). 
a la justicia y a la reparación a la luz de la jurisprudencia de la Corte IDH, desarrollada en casos de justicia transicional y en el marco de dicho análisis, cuando sea pertinente, se tratará transversalmente la importancia de las garantías de no repetición.

Las consideraciones del Tribunal Interamericano son de gran importancia en este tema pues es el único órgano jurisdiccional regional de derechos humanos que ha analizado la convencionalidad de mecanismos de justicia transicional, como amnistías e indultos, comisiones de la verdad y mecanismos de reparación administrativa, en contextos de transición de dictadura a democracia y de conflicto armado a paz. ${ }^{4}$

Este desarrollo jurisprudencial, que será objeto de análisis en el presente texto, lo ha hecho la Corte en dos contextos diferentes, que han marcado la historia latinoamericana. Por un lado, tras la caída de los regímenes dictatoriales en el Cono Sur y el proceso de restablecimiento de la democracia en Perú, ${ }^{5}$ Chile, ${ }^{6}$ Uruguay $^{7}$ y Brasil. $^{8}$ Y, por el otro lado, en el marco del tránsito del conflicto armado a la paz, tras un proceso de negociación entre las partes, en El Salvador ${ }^{9}$ y Colombia. ${ }^{10}$

4 Federico Cersale di Cerisano, Justicia transicional en las Américas. El impacto del Sistema Interamericano, Revista IIDH, 57, 115-136 (2013).

5 Corte IDH, Caso Barrios Altos contra Perú. Sentencia del 14 de marzo de 2001. Fondo y Corte IDH, Caso La Cantuta contra Perú. Sentencia del 29 de noviembre de 2006. Fondo, reparaciones y costas.

6 Corte IDH, Caso Almonacid Arellano contra Chile. Sentencia del 26 de septiembre de 2006. Excepciones preliminares, fondo, reparaciones y costas.

7 Corte IDH, Caso Gelman contra Uruguay. Sentencia del 24 de febrero de 2011. Fondo y reparaciones.

8 Corte IDH, Caso Gomes Lund y otros ("Guerrilha do Araguaia") contra Brasil. Sentencia del 24 de noviembre de 2010. Excepciones preliminares, fondo, reparaciones y costas.

9 Corte IDH, Caso Masacres de El Mozote y lugares aledaños contra El Salvador. Sentencia del 25 de octubre de 2012. Fondo, reparaciones y costas y Corte IDH, Caso Rochac Hernández contra El Salvador. Sentencia del 14 de octubre de 2014. Fondo, reparaciones y costas.

10 El caso de Colombia es de especial importancia, en la medida en que, a pesar de permanecer en un contexto de conflicto armado, ha desarrollado e implementado mecanismos de justicia transicional que han sido analizados por la Corte Interamericana. Véase Corte IDH, Caso Masacre de Santo Domingo contra Colombia. Sentencia del 30 de noviembre de 2012. Excepciones preliminares, fondo y reparaciones; Corte IDH, Caso Comunidades afrodescendientes desplazadas de la cuenca del río Cacarica (Operación Génesis) contra Colombia. Sentencia del 20 de noviembre de 2013. Excepciones preliminares, fondo, reparaciones y costas; Corte IDH, Caso Rodríguez Vera y otros (Desaparecidos del Palacio de Justicia) contra Colombia. Sentencia del 14 de noviembre de 2014. Excepciones preliminares, fondo, reparaciones y costas. Corte IDH, Caso Yarce y otras contra Colombia. 
A continuación entonces se revisará el pasado, presente y futuro del 1) derecho a la verdad, 2) derecho a la justicia y 3) derecho a la reparación, en el marco de la llamada justicia transicional y a la luz de la jurisprudencia de la Corte Interamericana de Derechos Humanos. El análisis con respecto al caso colombiano se incluirá transversalmente en estas tres secciones del artículo y se expondrán algunas lecciones aprendidas y perspectivas en relación con este caso, en las conclusiones.

\section{PASADO, PRESENTE Y FUTURO DEL DERECHO A LA VERDAD}

La Convención Americana sobre Derechos Humanos no reconoce expresamente el "derecho a la verdad". Sin embargo, la jurisprudencia del tribunal ha reconocido que este se desprende de la interpretación de los derechos a las garantías judiciales, a la protección judicial y, más recientemente, del derecho a la libertad de expresión. ${ }^{11}$

En cuanto a su contenido, el análisis del derecho a la verdad en la jurisprudencia de la Corte Interamericana ha tenido dos evoluciones importantes y relevantes para efectos de la justicia transicional. La primera es el paso de su reconocimiento como derecho con una dimensión exclusivamente individual, a su concepción como un derecho con una importante dimensión colectiva.

La dimensión individual considera que el derecho a la verdad pertenece exclusivamente a las víctimas y a sus familiares. ${ }^{12}$ Esta

Sentencia del 22 de noviembre de 2016. Excepción preliminar, fondo, reparaciones y costas.

11 En el caso Barrios Altos contra Perú, la Corte Interamericana señaló que el derecho a la verdad se subsume en los derechos a las garantías judiciales y a la protección judicial. Ahora bien, desde 2010, con el caso Gomes Lund contra Brasil y, posteriormente, con los casos Gelman contra Uruguay y Masacres de El Mozote contra El Salvador, la Corte indicó que el derecho a la verdad también encontraba fundamento en el artículo 13 de la Convención Americana de Derechos Humanos (CADH), en tanto las víctimas y sus familiares tienen el derecho a buscar y recibir información, entre otros asuntos, sobre los hechos que constituyen violaciones a los derechos humanos, sus responsables y sus móviles.

12 Luis Fajardo, Elementos estructurales del derecho a la verdad, Civilizar 15, 15-33 (2012); 
perspectiva que fue abordada por ejemplo en el caso Barrios Altos contra Perú, no resultaba suficiente, especialmente en contextos en los que han ocurrido graves y masivas violaciones a los derechos humanos e infracciones al derecho internacional humanitario. Por ello, la Corte avanzó en distintas aproximaciones de la dimensión colectiva del derecho a la verdad en contextos de justicia transicional.

Así, en el caso La Cantuta contra Perú, la Corte se aproximó a una primera faceta de esta dimensión del derecho a la verdad, relacionada con las investigaciones penales. En ese caso, el Tribunal afirmó que los resultados de las investigaciones deben ser divulgados públicamente "de manera que la sociedad peruana pueda conocer la verdad acerca de los hechos del presente caso". ${ }^{13}$

Sin embargo, no fue sino hasta el caso de Gomes Lund $y$ otros contra Brasil que la Corte reconoció expresamente la dimensión colectiva del derecho a la verdad en un marco de justicia transicional. ${ }^{14}$ Este criterio fue luego reiterado en casos posteriores. ${ }^{15}$ Según la Corte "los familiares de las víctimas $y$ la sociedad, deben ser informados de todo lo sucedido en relación con dichas violaciones"16 (itálicas fuera del texto original). Esto, a consideración del Tribunal Interamericano, implica que el Estado: 1) ubique, ${ }^{17}$ organice y sistematice la informa-

Damián González, El derecho a la verdad en situaciones de post-conflicto bélico de carácter no internacional, Int. Law: Rev. Colomb. Derecho Int. 13, $435-467$ (2008); Yasmin Naqvi, The Right to the Truth in International Law: Fact or Fiction? International Review of the Red Cross 88, 245-273 (2006); Thomas Antkowiak, Truth as a Right and Remedy in International Human Rights Experience, 23 Mich. J. INT'L L, 977-999 (2001).

13 Corte IDH, Caso La Cantuta contra Perú. Sentencia del 29 de noviembre de 2006. Fondo, reparaciones y costas, párr. 228.

14 Corte IDH, Caso Gomes Lund y otros ("Guerrilha do Araguaia") contra Brasil. Sentencia del 24 de noviembre de 2010. Excepciones preliminares, fondo, reparaciones y costas, párr. 200.

15 Corte IDH, Caso Masacres de El Mozote y lugares aledaños contra El Salvador. Sentencia del 25 de octubre de 2012. Fondo, reparaciones y costas, párr. 298; Corte IDH, Caso Gelman contra Uruguay. Sentencia del 24 de febrero de 2011. Fondo y reparaciones, párr. 243.

16 Corte IDH, Caso Gomes Lund y otros ("Guerrilha do Araguaia") contra Brasil. Sentencia del 24 de noviembre de 2010. Excepciones preliminares, fondo, reparaciones y costas, párr. 200.

17 Corte IDH, Caso Gomes Lund y otros ("Guerrilha do Araguaia”) contra Brasil. Sentencia del 24 de noviembre de 2010. Excepciones preliminares, fondo, reparaciones y costas, párr. 210. 
ción relacionada con violaciones a derechos humanos: ${ }^{18}$ 2) cree plataformas y mecanismos que permitan el acceso público y la consulta a autoridades administrativas y judiciales, víctimas o familiares y sociedad en general, ${ }^{19}$ y 3 ) no limite el acceso a la información, buscando ampararse en "el secreto de Estado o la confidencialidad de la información o en razones de interés público o seguridad nacional". ${ }^{20}$

Esta nueva perspectiva en la titularidad del derecho fue absolutamente fundamental en la evolución de su concepción. Reconocer que la sociedad tiene derecho a conocer la verdad de lo sucedido no implica solamente la ampliación de la concepción de los sujetos titulares de los derechos, hacia una visión colectiva representada incluso en toda la sociedad, sino que significa también reconocer que la visión sobre la satisfacción solo individual del derecho debe también ceder ante el derecho de las sociedades a conocer.

Por último, una perspectiva interesante de las diversas dimensiones del derecho a la verdad, la presenta el juez García-Sayán en su voto concurrente del caso Masacres del Mozote contra El Salvador. El juez afirma que existen tres dimensiones de la verdad:

La "factual" le da a la familia información concreta sobre el paradero de los restos mortales de la víctima o sobre lo que pasó. La "personal" procura un efecto catártico en la persona que expresa o manifiesta esa verdad. La "social" es la que la sociedad adopta a través del diálogo y el debate. En la búsqueda de esta "verdad social" juegan un papel importante medidas como la apertura de la documentación en manos del Estado, la revisión de los textos escolares y la construcción de museos o memoriales de lo ocurrido. ${ }^{21}$

18 Corte IDH, Caso Masacres de El Mozote y lugares aledaños contra El Salvador. Sentencia del 25 de octubre de 2012. Fondo, reparaciones y costas, párr. 321 y Corte IDH Caso Gomes Lund y otros ("Guerrilha do Araguaia") contra Brasil. Sentencia del 24 noviembre de 2010. Excepciones preliminares, fondo, reparaciones y costas, párr. 280.

19 Corte IDH, Caso Masacres de El Mozote y lugares aledaños contra El Salvador. Sentencia del 25 de octubre de 2012. Fondo, reparaciones y costas, párr. 321.

20 Corte IDH, Caso Gomes Lund y otros ("Guerrilha do Araguaia") contra Brasil. Sentencia del 24 de noviembre de 2010. Excepciones preliminares, fondo, reparaciones y costas, párr. 202.

21 Voto concurrente del Juez Diego García-Sayán. Sentencia de la Corte IDH, Caso Masacres de 
Ahora bien, una segunda perspectiva de esta evolución se presenta, ya no ante el contenido del derecho a la verdad, sino ante los niveles requeridos para su satisfacción. En la sentencia Gelman contra Uruguay, la Corte IDH afirmó que, en su dimensión individual, el derecho se satisface con el esclarecimiento de los hechos y sus responsables; mientras que en su dimensión colectiva...

[...] el derecho a la verdad exige la determinación procesal de la más completa verdad histórica posible, lo cual incluye la determinación judicial de los patrones de actuación conjunta y de todas las personas que de diversas formas participaron en dichas violaciones y sus correspondientes responsabilidades. ${ }^{22}$

Pareciera, entonces, que desde esta perspectiva la Corte analiza la satisfacción del derecho a la verdad exclusivamente por medio de los resultados de los procesos judiciales y particularmente de los procesos penales, lo cual resta importancia a otros mecanismos extrajudiciales expresamente destinados a la satisfacción del derecho a la verdad en procesos de justicia transicional.

Por ello ha resultado tan importante que recientemente el Tribunal Internacional también haya tenido que avocarse a conocer sobre el valor y alcance de las Comisiones de la Verdad, como mecanismos extrajudiciales de justicia transicional. En relación con el valor de estas comisiones, en el caso Gomes Lund contra Brasil, la Corte reconoció el establecimiento de la Comisión como un mecanismo de reparación, debido a que puede "contribuir a la construcción y preservación de la memoria histórica, al esclarecimiento de hechos y a la determinación de responsabilidades institucionales, sociales y políticas en determinados periodos históricos de una sociedad". ${ }^{23}$

El Mozote y lugares aledaños contra El Salvador. 25 de octubre de 2012, párr. 25.

22 Corte IDH, Caso Gelman contra Uruguay. Sentencia del 24 de febrero de 2011. Fondo y reparaciones, párr. 192.

23 Corte IDH, Caso Gomes Lund y otros ("Guerrilha do Araguaia") contra Brasil. Sentencia del 24 de noviembre de 2010. Excepciones preliminares, fondo, reparaciones y costas, párr. 297. 
No obstante, en torno al alcance de las comisiones de la verdad, la posición de la Corte ha sido unánime y sostenida en el tiempo: a pesar de valorar este tipo de mecanismos, ha afirmado que la "verdad histórica" contenida en sus informes no puede sustituir la obligación del Estado de lograr la verdad mediante los procesos judiciales.

No cabe duda, en consecuencia, que la Corte IDH le ha dado un valor indiscutible a los procesos judiciales para satisfacer el derecho a la verdad. Desde nuestro punto de vista y de cara justamente a la estrategia integral de justicia transicional en Colombia, esta visión tan limitada del rol de las comisiones de la verdad resulta problemática. Si bien es cierto que este tipo de comisiones no sustituirá enteramente los procesos judiciales, sí podrá resultar un complemento importante para la satisfacción del derecho a la verdad y especialmente para la satisfacción de su dimensión colectiva, tal como se anuncia incipientemente en el caso Gomes Lund.

En este sentido, y sin perjuicio de los debates que puedan darse en torno al reconocimiento del sujeto "sociedad" como titular de los derechos convencionales, ${ }^{24}$-cuestión sobre la que no nos ocuparemos en el presente texto-, lo que sí resulta importante destacar es que esta dimensión colectiva debe también, indefectiblemente, tener consecuencias sobre la interpretación de los derechos a la verdad, a la justicia y a la reparación en el marco de la justicia transicional. En efecto, en la medida en que los mecanismos de justicia transicional deban satisfacer los derechos de la sociedad como un todo, y no únicamente los derechos individuales de las víctimas, el diseño de las herramientas deberá adaptarse para lograr la máxima satisfacción posible de ambas dimensiones (la individual y la colectiva), lo cual implicará necesariamente abordar la satisfacción de los derechos desde perspectivas novedosas y relativamente flexibles, sin desconocer

24 Sobre esta discusión véase, por ejemplo, Gurutz Jáuregui, Derechos individuales versus derechos colectivos. Una realidad inescindible, en Una discusión sobre derechos colectivos, 40-47 (Francisco Ansuátegui, Dykinson S.L., Madrid, 2008); Michael Freeman, Are there Collective Human Rights?, Political Studies 43, 25-40 (1995). 
las mínimas garantías que deben respetar todos los Estados, a propósito de tales derechos.

Quizás el futuro de la evolución del derecho a la verdad en contextos de justicia transicional recaiga en el análisis de la estrategia integral en Colombia y en la relación de complementariedad que existirá entre la Comisión de la Verdad, la Jurisdicción Especial para la Paz y la justicia ordinaria..$^{25}$ Esta puede ser una oportunidad para avanzar en el reconocimiento de novedosas interpretaciones.

\section{PASADO, PRESENTE Y FUTURO DEL DERECHO A LA JUSTICIA}

Un tema recurrente y ampliamente citado en relación con la jurisprudencia de la Corte Interamericana es el alcance de la obligación de investigar, juzgar y sancionar en contextos de justicia transicional. Al respecto, las opiniones varían mucho desde aquellos que consideran que la posición de la Corte es muy clara y unánime y que el deber de investigar, juzgar y sancionar es tan importante, que pertenece incluso a la esencia de las Constituciones Políticas de los países democráticos; ${ }^{26}$ hasta aquellos que

25 El Acuerdo de Paz firmado entre el Gobierno nacional y las FARC establece de forma expresa que la Comisión de la Verdad "no puede entenderse de manera aislada del Sistema Integral, que incluye mecanismos judiciales y extrajudiciales para garantizar los derechos de las víctimas a la verdad, la justicia y la reparación, además de contribuir a garantizar a los colombianos y las colombianas la no repetición del conflicto". Así, la relación entre la Comisión, la jurisdicción ordinaria y la jurisdicción especial para la paz, puede verse desde tres perspectivas: en primer lugar, la Comisión de la Verdad tendrá acceso a las investigaciones e información recolectada por magistrados, jueces y organismos de investigación. En segundo lugar, como requisito para que los actores del conflicto armado puedan acogerse al tratamiento especial de la Jurisdicción Especial para la Paz, deberán aportar la verdad plena; esto es "relatar, cuando se disponga de los elementos para ello, de manera exhaustiva y detallada las conductas cometidas y las circunstancias de su comisión, así como las informaciones necesarias y suficientes para atribuir responsabilidades". Por último, las sentencias en firme que profiera el Tribunal para la Paz serán remitidas de forma inmediata a la Comisión para el Esclarecimiento de la Verdad. Véase Acuerdo Final para la terminación del conflicto y la construcción de una paz estable y duradera. Punto 5 .

26 Véase por ejemplo, Comisión Colombiana de Juristas. Demanda contra el Marco Jurídico para la Paz. Presentada ante la Corte Constitucional del Colombia. 29 de diciembre de 2012. Disponible en: http://www.iccnow.org/documents/ColJuristasdemanda.pdf; Rodrigo Uprimny, Justicia para la paz. Crímenes atroces, derecho a la justicia y paz negociada, I, 28-30 (1 Ed., Dejusticia, Bogotá, 2014). 
opinan que no existe un deber de investigar, juzgar y sancionar que se derive de la Convención Americana. ${ }^{27}$ No nos inscribimos en ninguna de estas dos posturas, que consideramos extremas. La posición intermedia con la que nos identificamos es que si bien el deber de investigar, juzgar y sancionar sí se deriva de la Convención Americana, la jurisprudencia en este aspecto sigue siendo poco clara, sigue abierta a muchos debates y requiere de un importante desarrollo, especialmente para su aplicación en contextos de justicia transicional.

\section{A. En relación con las amnistías}

A pesar de que existe un imaginario común de que la jurisprudencia de la Corte Interamericana es muy clara en relación con los límites para proferir leyes de amnistía y autoamnistía, lo cierto es que de la lectura de la jurisprudencia no se desprende que haya realmente un consenso definido sobre estos límites. La expresión más común de la jurisprudencia de la Corte en este aspecto, cuyo caso hito es la sentencia Barrios Altos contra Perú y que se deriva principalmente de los casos que se han referido a transiciones de la dictadura a democracia, es que están prohibidas las amnistías que impidan la investigación, el juzgamiento y la sanción de violaciones graves a los derechos humanos. ${ }^{28}$

Sin embargo, el alcance de las amnistías no está realmente claro en la jurisprudencia. Por ejemplo, solo en el caso Almonacid Arellano contra Chile se encuentran al menos ocho expresiones diferentes -en distintas partes del fallo-que buscan, justamente, aproximarse a sus límites. Así, en ese caso, la Corte afirmó que se deberán investigar, juzgar y sancionar y por tanto estarán prohibidas las amnistías ante 1) crímenes de lesa humanidad;29

27 Véase, por ejemplo, Christian Tomuschat, Common Values and the Place of the Charter in Europe, European review of public 12, 14, 159-191 (2002). Rodrigo Uprimny, Justicia para la paz. Crímenes atroces, derecho a la justicia y paz negociada, I, 28-30 (1 Ed., Dejusticia, Bogotá, 2014).

28 Corte IDH Caso Barrios Altos contra Perú. Sentencia del 14 de marzo de 2001. Fondo, párr. 41.

29 Corte IDH, Caso Almonacid Arellano contra Chile. Sentencia del 26 de septiembre de 2006. Excepciones preliminares, fondo, reparaciones y costas, párr. 106. 
2) infracciones graves al $\mathrm{DIH} ;{ }^{30}$ 3) serias violaciones al derecho internacional; ${ }^{31}$ 4) crímenes de guerra; ${ }^{32}$ 5) crímenes internacionales, ${ }^{33} 6$ ) violaciones de los derechos reconocidos por la Convención ${ }^{34}$ y 7) graves violaciones a los derechos humanos. ${ }^{35}$ Esta falta de claridad se hace también evidente en otros casos abordados por el Tribunal. Por ejemplo, en el caso La Cantuta contra Perú, la Corte retoma la sentencia del caso Barrios Altos para señalar que la Ley de Amnistía N. 26.479 no tiene efectos jurídicos, ${ }^{36}$ pero al abordar los límites de las amnistías acude a la regla del caso Almonacid Arellano en la que señala la prohibición de estas disposiciones para responsables de crímenes de lesa humanidad. ${ }^{37}$

En el mismo sentido, en el caso Gomes Lund contra Brasil, a pesar de que la Corte señala que hay consenso sobre los límites de las amnistías, las disposiciones citadas evidencian diferentes posturas y expresiones que varían desde las graves violaciones a los derechos humanos, ${ }^{38}$ los crímenes internacionales, ${ }^{39}$ los delitos en el derecho internacional, ${ }^{40}$ hasta incluso los delitos "en la legislación nacional", ${ }^{41}$ entre los que se encontrarían la tortura y otros tratos crueles, inhumanos o degradantes, las privaciones sumarias y arbitrarias de la vida y las desapariciones forzosas. ${ }^{42}$

30 Corte IDH, Caso Almonacid Arellano contra Chile, cit. supra nota 29, párr.109.

31 Corte IDH, Caso Almonacid Arellano contra Chile, cit. supra nota 29, párr. 107.

32 Corte IDH, Caso Almonacid Arellano contra Chile, cit. supra nota 29, párr. 106.

33 Corte IDH, Caso Almonacid Arellano contra Chile, cit. supra nota 29, párr. 108.

34 Corte IDH, Caso Almonacid Arellano contra Chile, cit. supra nota 29, párr. 110.

35 Corte IDH, Caso Almonacid Arellano contra Chile, cit. supra nota 29, párr. 112.

36 Corte IDH, Caso La Cantuta contra Perú. Sentencia del 29 de noviembre de 2006. Fondo, reparaciones y costas.

37 Corte IDH, Caso Almonacid Arellano contra Chile. Sentencia del 26 de septiembre de 2006. Excepciones preliminares, fondo, reparaciones y costas, párr. 114.

38 Corte IDH, Caso Gomes Lund y otros ("Guerrilha do Araguaia”) contra Brasil. Sentencia del 24 de noviembre de 2010. Excepciones preliminares, fondo, reparaciones y costas, párr. 147.

39 Corte IDH, Caso Gomes Lund y otros ("Guerrilha do Araguaia") contra Brasil, cit. supra nota 38, párr. 159.

40 Corte IDH, Caso Gomes Lund y otros ("Guerrilha do Araguaia”) contra Brasil, cit. supra nota 38 , párr. 156.

41 Corte IDH, Caso Gomes Lund y otros ("Guerrilha do Araguaia") contra Brasil, cit. supra nota 38 , párr. 156.

42 Corte IDH, Caso Gomes Lund y otros ("Guerrilha do Araguaia”) contra Brasil, cit. supra nota 38, párr. 171. 
Algo muy similar ocurre en el caso Gelman contra Uruguay, en el que la Corte sigue utilizando distintas expresiones para referirse al mismo límite. ${ }^{43}$ Este caso es interesante en cuanto además cita el artículo 6.5 del Protocolo II Adicional a los Convenios de Ginebra, que establece que los Estados deberán otorgar la "amnistía más amplia posible" al final de las hostilidades. No obstante, es preciso aclarar que el Tribunal acude a esta disposición únicamente para referirse a la prohibición de otorgar amnistías a crímenes de guerra. ${ }^{44}$

Cuestión distinta será el uso de esta misma norma del derecho internacional humanitario en la sentencia de Masacres de El Mozote, primer caso en el que la Corte se refirió a una transición del conflicto armado hacia una paz negociada en un Estado del continente. En dicho caso, la Corte utiliza el artículo 6.5, junto con la regla consuetudinaria $\mathrm{N}^{\circ} 159$ del DIH con un sentido más "permisivo" y quizá "conciliador", en la medida en que avaló las amnistías, en contextos de transición de conflicto armado a paz, salvo para los responsables de cometer crímenes de guerra y crímenes de lesa humanidad. ${ }^{45}$

Así, el artículo 6.5 no se enuncia en El Mozote como un desarrollo más en el derecho internacional de los derechos humanos sobre el límite de las amnistías -como ocurre en el caso Gelman-, sino como el fundamento ${ }^{46}$ de lo que, a consideración nuestra,

43 En este caso, la Corte Interamericana también señala como límites de las amnistías 1) los crímenes internacionales; 2) los crímenes de guerra; 3) los crímenes de lesa humanidad; 4) las violaciones graves a los derechos humanos o 5) "toda disposición que tenga por efecto la impunidad”. Corte IDH, Caso Gelman contra Uruguay. Sentencia del 24 de febrero de 2011. Fondo y reparaciones.

44 Corte IDH, Caso Gelman contra Uruguay. Sentencia del 24 de febrero de 2011. Fondo y reparaciones, párr. 210.

45 Corte IDH, Caso Masacres de El Mozote y lugares aledaños contra El Salvador. Sentencia del 25 de octubre de 2012. Fondo, reparaciones y costas, párr. 286.

46 La Corte Interamericana hizo el siguiente razonamiento: "284. Sin embargo, y a diferencia de los casos abordados anteriormente por este Tribunal, en el presente caso se trata de una ley de amnistía general que se refiere a hechos cometidos en el contexto de un conflicto armado interno. Por ello, la Corte estima pertinente, al realizar el análisis de la compatibilidad de la Ley de Amnistía General para la Consolidación de la Paz con las obligaciones internacionales derivadas de la Convención Americana y su aplicación al caso de las Masacres de El Mozote y lugares aledaños, hacerlo también a la luz de lo establecido en el Protocolo II adicional a los Convenios de Ginebra de 1949" (negrilla fuera de texto original). 
constituye un cambio o al menos una contextualización de la jurisprudencia anterior de la Corte, que ya ha sido abordada.

Ahora bien, esta postura no es del todo pacífica, pues existen sectores de la doctrina que sostienen que de la sentencia de $E l$ Mozote no puede derivarse que realmente exista un estándar más flexible en los procesos de transición de conflicto armado a paz, en comparación con las transiciones de dictadura a democracia. ${ }^{47}$

Lo anterior se debe, en gran parte, a que, a pesar de que la Corte resalta la particularidad del caso -esto es, un proceso de transición de conflicto armado a paz-reitera, unos párrafos más arriba, que el límite de las amnistías son las violaciones graves a los derechos humanos; regla central que, hasta el momento, había sido aplicada a contextos de transición de dictadura a democracia. ${ }^{48}$

Sin desconocer esta confusión que surge con la falta de precisión de la Corte IDH, tras un análisis integral y sistemático de la sentencia, encontramos tres elementos que dan cuenta de una modificación al límite de las amnistías.

En primer lugar, y como ya se abordó en parte, la Corte expresamente reconoció que ante la diferente naturaleza del proceso de transición, se requería de la aplicación de disposiciones convencionales y consuetudinarias del Derecho Internacional Humanitario (DIH). ${ }^{49} \mathrm{Si}$ se aplicara el mismo estándar de las transiciones de dictadura a democracia, no habría sido necesario hacer tal clarificación.

En segundo lugar, el Tribunal condenó, finalmente, a El Salvador por haber otorgado amnistías que aplicaban a hechos que configuraban crímenes internacionales. Por último, la in-

47 Luis Gutiérrez, La obligación internacional de investigar, juzgar y sancionar graves violaciones a los derechos humanos en contextos de justicia transicional, Estudios Socio-Jurídicos 16, 2360 (2014).

48 Corte IDH, Caso Masacres de El Mozote y lugares aledaños contra El Salvador. Sentencia del 25 de octubre de 2012. Fondo, reparaciones y costas, párr. 283.

49 "A diferencia de los casos abordados anteriormente por este tribunal, en el presente caso se trata de una ley de amnistía general que se refiere a hechos cometidos en el contexto de un conflicto armado interno. Por ello, la Corte estima pertinente, al realizar el análisis de la compatibilidad de la Ley de Amnistía General para la Consolidación de la Paz [...] hacerlo también a la luz de lo establecido en el Protocolo II adicional a los Convenios de Ginebra de 1949”. 
terpretación del texto del fallo puede complementarse con el voto concurrente del juez García-Sayán, quien en compañía de cuatro jueces más desarrolló algunos criterios que permitirían diferenciar el alcance de las obligaciones del Estado en contextos de justicia transicional, cuando las transiciones sean de conflictos armados hacia la paz. Al respecto el juez señaló, entre otras cuestiones, que este tipo de transición supone la aplicación de normas específicas del DIH, a la hora de determinar el alcance de las amnistías, dándole mayor fuerza a la interpretación por medio del artículo 6.5 del Protocolo II. Desde nuestro punto de vista no podría entenderse que la sentencia no modificó en nada los estándares y jurisprudencia anterior (enmarcada en contextos de transiciones de dictaduras a democracia), pues de lo contrario estas apreciaciones del voto carecerían de efecto útil.

Ahora bien, vale la pena precisar que a pesar de que el caso de El Salvador es el más cercano al contexto colombiano, no puede tampoco afirmarse que los estándares desarrollados deben o pueden ser aplicados automáticamente al proceso vivido en el país, pues 1) el contexto; 2) el contenido y 3) el enfoque del Acuerdo de Paz difiere en gran manera al de Colombia. ${ }^{50}$

Por último, y para evidenciar aún más la falta de claridad y precisión del Tribunal Interamericano, no puede dejarse de mencionar que en 2014, en la sentencia de Rochac Hernández contra El Salvador, la Corte afirmó, nuevamente, que están prohibidas las amnistías en casos de graves violaciones a los derechos humanos, como la desaparición forzada. ${ }^{51}$ Esto resulta especialmente contradictorio pues a pesar de que la Corte abordaba la misma Ley de Amnistía de El Salvador y bajo el mismo contexto -transición de conflicto armado a paz-, el Tribunal retomó la regla que desarrolló desde el caso Barrios Altos contra Perú, para transiciones de dictadura a democracia.

50 Juana Acosta, The Inter-American Human Rights System and the Colombian Peace: Redefining the fight against impunity, AJIL Unbound, 1, 178-182 (2016).

51 Corte IDH, Caso Rochac Hernández contra El Salvador. Sentencia del 14 de octubre de 2014. Fondo, reparaciones y costas, párr. 212. 
Esta sentencia, en consecuencia, aumenta la inseguridad jurídica en virtud del precedente de la Corte en relación con este aspecto. ${ }^{52}$ Incertidumbre que es bastante problemática, porque adoptar cualquiera de estas dos posturas (límite graves violaciones a los derechos humanos o límite crímenes internacionales) genera consecuencias importantes. Esto, por cuanto, si bien todo crimen internacional es una grave violación a los derechos humanos, no toda grave violación a los derechos humanos es a la vez un crimen internacional.

La principal diferencia que se erige entre estos conceptos versa, entonces, en los supuestos que se requieren para su configuración. En el caso de las graves violaciones a los derechos humanos, solo se requerirá la acreditación de la comisión de las conductas que, históricamente, hayan sido reconocidas como tales. ${ }^{53}$ En cuanto a los crímenes internacionales, se deberá demostrar, además de la conducta que constituye una grave violación a los derechos humanos, la configuración de unos elementos contextuales, consignados expresamente en el Estatuto de Roma. ${ }^{54}$

Por tanto, el límite y la prohibición serán mucho más estrictos en la primera postura - casos de transición de dictadura a democracia-, y esto puede tener consecuencias concretas en la determinación de los alcances de las amnistías en un proceso de justicia transicional en particular.

El futuro de la jurisprudencia ante la prohibición de las amnistías, por tanto, depende también en buena medida del análisis que haga la Corte del caso colombiano. Sin duda, la Corte IDH deberá analizar el alcance tanto del Acuerdo de Paz, como de

52 Si bien se hace referencia al concepto de 'precedente', es relevante tener en cuenta que la Corte IDH, a diferencia del Tribunal Europeo de Derechos Humanos (TEDH), se ha abstenido de reconocer tal naturaleza a su jurisprudencia. Juana Acosta y Cindy Espitia, El valor del precedente en la Corte Interamericana de Derecho Humanos: vacíos, prácticas y lecciones, en $E l$ precedente judicial y el ejercicio del Derecho ante las altas Cortes, 393-411 (Leonardo López, Universidad de Medellín, Medellín, 2015).

53 La Corte IDH ha reconocido como violaciones graves a los derechos humanos la desaparición forzada, la tortura, las ejecuciones extrajudiciales y el apartheid.

54 Iryna Marchuk, The Fundamental Concept of Crime in International Criminal Law. Faculty of Law University of Copenhagen Copenhagen, Denmark. 2014. Chapter 4 The Concept of Crime in International Criminal Law, 69-113. 
la reciente ley de amnistía y del fallo que al respecto profiera la Corte Constitucional de Colombia. ${ }^{55}$ Esa será una oportunidad única para que el tribunal internacional aclare las reglas en relación con las amnistías, no solo por tratarse también de un contexto de transición del conflicto armado hacia la paz, sino porque será la primera vez que la Corte evalúe un sistema verdaderamente integral de mecanismos de justicia transicional derivados de una paz negociada. ${ }^{56}$.

\section{B. ¿Investigar, juzgar y sancionar a todos los responsables?}

Pero al margen de la pregunta sobre las amnistías, una vez definido el rango de crímenes que efectivamente deben ser investigados en un contexto de justicia transicional ¿a quiénes se debe investigar? ¿A todos los responsables? o ¿solo a los máximos responsables? Al respecto, la jurisprudencia de la Corte IDH, por regla general, se refiere al deber de investigar, juzgar y sancionar a todos los responsables intelectuales y materiales de los hechos, especialmente cuando están involucrados agentes estatales. Esta regla fue reiterada por la Corte en casos, tanto de transiciones de la dictadura a la democracia, ${ }^{57}$ como en casos de transición de conflicto armado hacia la paz. ${ }^{58}$

55 Tras la aprobación de la Ley 1820 de 2016, mediante el procedimiento de fast track, el Presidente de la República promulgó la norma y la remitió a la Corte Constitucional, órgano que en la actualidad se encuentra deliberando sobre la conformidad de las disposiciones de la ley a la luz de la Constitución y las obligaciones convencionales del Estado.

56 A pesar de que en El Salvador se establecieron mecanismos de justicia transicional como el otorgamiento de amnistías y la creación de la Comisión de la Verdad, no puede hablarse aún de la creación y consolidación de un sistema integral de justicia transicional. En Colombia, de conformidad con el punto 5 del Acuerdo Final de Paz, el Sistema está compuesto por la 1) Comisión de esclarecimiento de la verdad; 2) Comisión de búsqueda de personas desaparecidas y 3) la Jurisdicción Especial para la Paz, órganos que trabajarán de forma coordinada y complementaria. Acuerdo final para la terminación del conflicto y la construcción de una paz estable y duradera. 24 de noviembre de 2016. Punto 5.

57 Corte IDH, Caso Almonacid Arellano contra Chile. Sentencia del 26 de septiembre de 2006. Excepciones preliminares, fondo, reparaciones y costas, párr. 106 y Corte IDH, Caso Barrios Altos contra Perú. Sentencia del 14 de marzo de 2001. Fondo y Corte IDH, Caso La Cantuta contra Perú. Sentencia del 29 de noviembre de 2006. Fondo, reparaciones y costas.

58 Corte IDH, Caso Masacres de El Mozote y lugares aledaños contra El Salvador. Sentencia del 25 de octubre de 2012. Fondo, reparaciones y costas, párr. 298. 
Sin embargo, en su voto concurrente a la sentencia Masacres del Mozote contra El Salvador, los jueces signatarios aclararon que dada la particularidad de los contextos de justicia transicional de conflicto armado a paz, los Estados pueden 1) diseñar medidas como las penas alternativas y suspendidas; 2) distinguir entre los ejecutores y quienes desempeñaron funciones de mando y 3) abordar e identificar las responsabilidades de los diferentes actores del conflicto, especialmente de "los máximos líderes". ${ }^{59}$ Este razonamiento parecería aplicar más a casos que conocería la Corte IDH en el futuro (especialmente el caso colombiano) que al propio caso de El Salvador, para el que no se diseñaron este tipo de medidas alternativas.

Lo interesante es que en casos colombianos, en los que no se han abordado directamente los mecanismos de justicia transicional, la Corte IDH ha evolucionado considerablemente en la flexibilidad de criterios sobre la investigación, juzgamiento y sanción de los responsables. Así, por ejemplo, tanto en el caso Santo Domingo contra Colombia, como en el Yarce y otras contra Colombia, la Corte afirmó que el Estado había cumplido con su obligación de investigar, juzgar y sancionar, aun cuando no se había investigado, juzgado y sancionado a todos los responsables de todos los hechos. Al respecto, en Santo Domingo la Corte expresamente afirmó que:

Para la Corte lo relevante es que los órganos de administración de justicia internos ya han determinado ampliamente varios alcances de la responsabilidad del Estado por los hechos, independientemente de los niveles de responsabilidad individual, penal o disciplinaria de los agentes estatales o de particulares, cuya definición corresponde a la jurisdicción interna, aun si no todos los hechos o calificaciones de los hechos han sido suficiente o totalmente investigados o esclarecidos. En tales términos, y en aplicación del principio de complementariedad, no habría sido necesario que la Corte se pronunciara sobre los hechos que generaron las violaciones de derechos reconocidas y reparadas a nivel interno, a saber, las que se refieren a los derechos a la vida, integridad

59 Voto concurrente del juez Diego García-Sayán. Sentencia de la Corte IDH, Caso Masacres de El Mozote y lugares aledaños contra El Salvador. 25 de octubre de 2012, párr. 30. 
personal y medidas especiales de protección para los niños. ${ }^{60}$ (Subrayas fuera del texto original)

Desde nuestro punto de vista, una interpretación adecuada y coherente de la jurisprudencia de la Corte IDH no admitiría que, en situaciones ordinarias, este tribunal flexibilice su posición con respecto a los niveles de responsabilidad que deben ser investigados $\mathrm{y}$, en cambio, la mantenga en contextos de justicia transicional en donde las circunstancias contextuales justamente exigen diferentes fórmulas de investigación.

De hecho, esta interpretación más sistemática de la jurisprudencia del tribunal internacional fue lo que permitió que la Corte Constitucional de Colombia afirmara que en el marco de la estrategia de justicia transicional era posible aplicar las herramientas de priorización y selección, para el juzgamiento de los crímenes cometidos en el marco del conflicto armado. ${ }^{61}$

En este sentido, como en los otros casos, la prueba ácida de los alcances de esta regla radicará en el estudio del caso colombiano que haga la Corte Interamericana. Hasta el momento, el Tribunal no ha tenido que analizar directamente los criterios de priorización y selección en el marco de la justicia transicional en Colombia, especialmente si se tiene en cuenta que no ha empezado a operar formalmente la jurisdicción especial para la paz ni se ha implementado aún la ley de amnistía. Sin embargo, una vez inicie el funcionamiento formal de estas estrategias de justicia transicional, la mayoría de los casos que estudie la Corte seguramente tendrá que incluir el abordaje de alguno de estos mecanismos. En ese momento se pondrá a prueba el precedente, con sus respectivas implicaciones y la Corte tendrá la oportunidad de dar seguridad jurídica a la implementación del Acuerdo de Paz en Colombia.

60 Corte IDH, Caso Masacre de Santo Domingo contra Colombia. Sentencia del 30 de noviembre de 2012. Excepciones preliminares, fondo y reparaciones, párr. 171.

61 Corte Constitucional de la República de Colombia, Sala Plena, Sentencia C-579 de 2013, 28 de agosto de 2013, Expediente D-9499. Magistrado sustanciador: Jorge Ignacio Pretelt Chaljub; Corte Constitucional de la República de Colombia, Sala Plena, Sentencia C-694 de 2015, 11 de noviembre de 2015, Expediente D-9818. Magistrado ponente: Alberto Rojas Ríos. 


\section{PASADO, PRESENTE Y FUTURO DEL DERECHO A LA REPARACIÓN}

Como anunciamos desde la introducción, en relación con la reparación, uno de los temas más relevantes para efectos de la justicia transicional es el valor que el tribunal internacional le ha dado a los programas de reparación administrativa implementados en los distintos países.

En la jurisprudencia del pasado, en los casos Barrios Altos contra Perú y Masacres de El Mozote contra El Salvador no se establecieron criterios diferenciados de reparación para un contexto de justicia transicional. Sin embargo, esto no puede atribuirse exclusivamente a que la Corte IDH no estuviera abierta a avanzar en estos criterios, sino más bien se pudo deber a que en esos casos los Estados no presentaron ante la Corte elementos que permitieran al tribunal analizar programas especiales de reparación en contextos de justicia transicional.

El caso de Almonacid Arellano fue el primero en el que la Corte se pronunció sobre un programa administrativo de reparaciones, sentando una posición favorable en cuanto a su admisibilidad y conformidad con las obligaciones estatales. En este asunto, el Tribunal encontró probado que Chile había impulsado una política de reparaciones por las violaciones perpetradas durante la dictadura militar, que había beneficiado a las víctimas del caso.

La importancia del caso radica especialmente en que la Corte además de "celebrar los pasos dados por el Estado" en materia de indemnización por medio del programa, avala los montos otorgados por el Estado, concluye su conformidad con el artículo 63.1 y se abstiene de ordenar el pago adicional de los alegados daños morales. ${ }^{62}$

Ahora bien, dada la particularidad del caso y la complejidad de los procesos de transición, esta pudo ser una excelente oportunidad para que la Corte precisara y profundizara en los

62 Corte IDH, Caso Almonacid Arellano contra Chile. Sentencia del 26 de septiembre de 2006. Excepciones preliminares, fondo, reparaciones y costas, párr. 181. 
supuestos básicos y necesarios que podrían tener los programas administrativos para ponderar la obligación de reparar a las víctimas con la dificultad material que supone para el Estado satisfacer en su integralidad a ese inmenso universo de personas que ha visto menoscabados sus derechos, en un contexto de masivas violaciones. No obstante, ni en esta oportunidad ni en los siguientes casos, como se verá a continuación, la Corte ha fijado parámetros concretos que sirvan de guía para los Estados.

En el caso La Cantuta contra Perú, el Estado dio a conocer la promulgación de la Ley N. 28592 "que Crea el Plan Integral de Reparaciones (PIR)". Si bien la Corte resaltó que "este tipo de leyes refleja una voluntad de reparar" las graves violaciones a los derechos humanos, ${ }^{63}$ el Tribunal se abstuvo de analizar los alcances de la disposición por cuanto 1) no se había demostrado su aplicación al caso concreto y 2) la definición de víctima de la ley no incluía a las personas que hubieran recibido reparaciones por otra vía. ${ }^{64}$

De este caso se desprende entonces que para la Corte, la mera enunciación en abstracto de los programas de reparación y sus ventajas no es suficiente para que, en virtud del principio de complementariedad, se abstenga de fijar las reparaciones correspondientes.

Posteriormente, en el caso Gelman contra Uruguay ocurre un inexplicable retroceso. A pesar de que el Estado puso en conocimiento la promulgación de la Ley 18.596 sobre la "Actuación ilegítima del Estado entre el 13 de junio de 1968 y el 28 de febrero de 1985. Reconocimiento y reparación a las víctimas", la Corte no se pronunció sobre la idoneidad del programa ni sobre las razones por las cuales procedía a ordenar, de forma directa, los montos indemnizatorios a las víctimas directas e indirectas. ${ }^{65}$

63 Corte IDH, Caso La Cantuta contra Perú. Sentencia del 29 de noviembre de 2006. Fondo, reparaciones y costas, párr. 90 .

64 Corte IDH, Caso La Cantuta contra Perú. Sentencia del 29 de noviembre de 2006. Fondo, reparaciones y costas, párr. 212.

65 Corte IDH, Caso Gelman contra Uruguay. Sentencia del 24 de febrero de 2011. Fondo y reparaciones, párr. 287. 
En el caso Gomes Lund contra Brasil, la Corte dio un paso importante en la medida en que, además de abstenerse de ordenar nuevos montos indemnizatorios a las víctimas directas, realizó una primera aproximación a algunos criterios que deben guiar los programas de reparación administrativa. Así, indicó que:

De existir mecanismos nacionales para determinar formas de reparación, esos procedimientos y resultados deben ser valorados. Si esos mecanismos no satisfacen criterios de objetividad, razonabilidad y efectividad para reparar adecuadamente las violaciones de derechos reconocidos en la Convención declaradas por este Tribunal, corresponde a este, en ejercicio de su competencia subsidiaria y complementaria, disponer las reparaciones pertinentes. ${ }^{66}$

Asimismo, en el voto concurrente de Masacres del Mozote, los jueces sugirieron la idoneidad de programas masivos de reparación en contextos de transición de conflicto armado a paz.

Más recientemente, la Corte ha estudiado los programas administrativos de reparación de Colombia, Guatemala y Perú. Los contenidos de esos pronunciamientos nos permiten concluir que la Corte tiene aún muchas preocupaciones a propósito de la implementación, alcance y sostenibilidad de los programas y que esto ha hecho que sus decisiones sobre el tema sean cada vez más tímidas y prudentes.

Este nuevo desarrollo jurisprudencial puede dividirse en dos etapas: la primera, en la que se observa una intención de la Corte IDH de respaldar abiertamente los programas de reparación administrativa y materializar el principio de complementariedad, establecido en el preámbulo de la Convención Americana sobre Derechos Humanos (CADH) y, la segunda, en la que se evidencia un mayor recelo y quizá timidez a la hora de permitir que las víctimas de los casos sometidos a su jurisdicción, sean reparadas bajo las condiciones y procedimientos de los programas administrativos internos.

66 Corte IDH, Caso Gelman contra Uruguay. Sentencia del 24 de febrero de 2011. Fondo y reparaciones, párr. 303. 
La primera etapa se produce en el marco del análisis realizado por la Corte IDH a la Ley de Víctimas de Colombia, en los casos Operación Génesis y Rodríguez Vera. En el primero de ellos, el Tribunal destacó la importancia y legitimidad de los programas administrativos de reparación en escenarios de justicia transicional-dada la dificultad de reparar al inmenso universo de víctimas- y señaló la necesidad de que estos mecanismos garanticen 1) la participación de las víctimas; 2) la razonabilidad y proporcionalidad de las medidas pecuniarias; 3) la inclusión de parámetros justos de distribución y 4) la contribución real a la situación de las víctimas. ${ }^{67}$

Así, habiendo valorado el programa implementado en Colombia, la Corte ordenó que se garantizara a las víctimas el acceso prioritario a las indemnizaciones administrativas ${ }^{68}$ y a los demás componentes de la reparación como las medidas habitacionales y de restitución de tierras. ${ }^{69}$

En el caso Rodríguez Vera, a pesar de que la Corte indicó que la Ley de Víctimas no había sido aportada al expediente y que los argumentos relacionados con el programa administrativo se habían hecho de forma extemporánea, reiteró el importante avance que constituía la disposición y permitió también que el Estado implementara la reparaciones otorgadas "a través de los programas de reparación establecidos a nivel interno, siempre y cuando sean acordes a las medidas ordenadas en la presente Sentencia".70

En esta etapa, entonces, 1) se abrieron las puertas a los programas de reparación administrativa; 2 ) se reconoció su legitimidad y conformidad con la CADH; 3) se resaltó su importancia en

67 Corte IDH, Comunidades afrodescendientes desplazadas de la cuenca del río Cacarica (Operación Génesis) contra Colombia. Sentencia del 20 de noviembre de 2013. Excepciones preliminares, fondo, reparaciones y costas, párr. 473.

68 Corte IDH, Comunidades afrodescendientes desplazadas de la cuenca del río Cacarica (Operación Génesis) contra Colombia, cit. supra nota 67, párr. 475.

69 Corte IDH, Comunidades afrodescendientes desplazadas de la cuenca del río Cacarica (Operación Génesis) contra Colombia, cit. supra nota 67, párr. 461.

70 Corte IDH, Caso Rodríguez Vera y otros (desaparecidos del Palacio de Justicia) contra Colombia. Sentencia del 14 de noviembre de 2014. Excepciones preliminares, fondo, reparaciones y costas, párr. 551. 
contextos de justicia transicional; 4) se permitió al Estado que reparara a las víctimas por medio de los programas internos, tanto en los componentes pecuniarios como no pecuniarios y 5) se brindó confianza al programa a pesar de que su éxito en la implementación no estaba plenamente garantizado.

En la segunda etapa, la Corte se ha abstenido de permitir que la reparación de los casos sometidos a su conocimiento se realice mediante los programas internos de reparación. En el caso Miembros de la Aldea Chichupac y comunidades vecinas del municipio de Rabinal contra Guatemala, la Corte ordenó directamente las reparaciones a las víctimas, en tanto el Estado no demostró que el Programa Nacional de Resarcimiento (PNR) 1) establecía con claridad los criterios empleados al momento de establecer los montos y conceptos de las indemnizaciones a favor de las víctimas; 2) comprendía una dimensión integral de la reparación y 3) garantizaba la continuidad del programa. ${ }^{71}$

En ese mismo sentido, la Corte, en el caso Tenorio Roca y otros contra Perú, concluyó que el Estado no había aportado la información suficiente que diera cuenta de "un resultado definitivo hasta el momento, debido a que no ha probado que alguna medida de reparación conforme al Plan Integral de Reparaciones (PIR), haya sido efectivamente otorgada a las víctimas hasta la fecha" ${ }^{72}$

Por último, en el caso Yarce y otras contra Colombia, la Corte, además de no remitir a las víctimas al programa de reparación administrativa por cuanto consideró que no se acreditó su efectividad en el asunto concreto, únicamente evaluó la posibilidad de aplicar los mecanismos internos en el componente indemnizatorio. $^{73}$

71 Corte IDH, Caso Miembros de la aldea Chichupac y comunidades vecinas del municipio de Rabinal contra Guatemala. Sentencia del 30 de noviembre de 2016. Excepciones preliminares, fondo, reparaciones y costas, párr. 333.

72 Corte IDH, Caso Tenorio Roca y otros contra Perú. Sentencia del 22 de junio de 2016. Excepciones preliminares, fondo, reparaciones y costas, párr. 279.

73 Corte IDH, Caso Yarce y otras contra Colombia. Sentencia del 22 de noviembre de 2016. Excepción preliminar, fondo, reparaciones y costas, párr. 328. 
De todo lo anterior pareciera deducirse que la clave para la jurisprudencia del futuro en materia de reparaciones, en contextos de justicia transicional, radica en el éxito de la implementación de los programas, lo cual le permitirá a los Estados presentar al tribunal pruebas más concretas y contundentes para que los fallos avalen las medidas y remitan a las víctimas a la reparación por medio de estos programas masivos.

De lo contrario, si la Corte IDH se abstiene completamente de apoyar y remitir a los programas internos de reparación, se obstaculizarán los esfuerzos del Estado por garantizar, ante la masividad del universo de las víctimas, una reparación con tendencia a la integralidad pues 1) se legitimaría que las víctimas acudan a la jurisdicción internacional, sin acudir a los recursos internos para solicitar la correspondiente reparación y 2) se afectaría la sostenibilidad del programa, en tanto la Corte IDH seguirá otorgando indemnizaciones que desbordan los montos fijados internamente. 


\section{CONCLUSIONES}

Del anterior análisis de la jurisprudencia de la Corte Interamericana, pueden identificarse las siguientes conclusiones y perspectivas de cara al derecho a la verdad, a la justicia y a la reparación en contextos de justicia transicional.

\section{A. Ante la jurisprudencia del pasado}

En primer lugar, a pesar del imaginario que existe sobre la claridad de los límites y alcances de los mecanismos de justicia transicional, en la jurisprudencia de la Corte IDH, se observa que no existen estándares precisos que otorguen seguridad jurídica a los Estados, con respecto a los tres derechos.

En segundo lugar, en relación con el derecho a la verdad, si bien ha existido una evolución - de la dimensión integral a la colectiva-, esta estuvo muy ligada a los avances en los procesos judiciales, por lo que no resultaba suficientemente claro el aporte o valor de los mecanismos extrajudiciales como las comisiones de verdad.

En tercer lugar, en materia de justicia, se observa que la Corte, en los casos relacionados con el proceso de transición de dictaduras a democracia, no ha fijado de forma clara los límites unívocos de los modelos implementados en tales contextos.

En cuarto lugar, en materia de reparación, la Corte fue reconociendo el valor de los programas administrativos de reparación. Sin embargo, no se observa un ejercicio de análisis y motivación de su parte que justifique bajo qué circunstancias es o no admisible la remisión al programa de reparación administrativo, desarrollado por el Estado.

\section{B. Ante la jurisprudencia del presente}

En primer lugar, en materia de verdad, a pesar de que la Corte ha proferido más sentencias que se refieren al rol de las comisiones 
de la verdad, su impacto y valor como mecanismo extrajudicial aún sigue siendo precario.

En segundo lugar, en materia de justicia, se observa que en la primera ocasión en la que la Corte IDH conoció de un proceso de transición de conflicto armado a paz -caso Masacres de El Mozote contra El Salvador-, el Tribunal resaltó la necesidad de aplicar las normas convencionales y consuetudinarias del DIH, para fijar el límite de las amnistías en tales contextos. Así, bajo el análisis sistemático de la sentencia, se puede encontrar que de acuerdo con la Corte, tras el fin de un conflicto armado, el Estado podrá otorgar amnistías salvo a los responsables de cometer crímenes internacionales o crímenes de guerra.

Ahora bien, a pesar de esto, sigue existiendo un vacío y una gran confusión debido a que en casos posteriores -como el de Rochac Hernández contra El Salvador-, el Tribunal ha reiterado la regla, más estricta, desarrollada en los casos de transición de dictadura a democracia, en virtud de la cual el límite de las amnistías son las violaciones graves a los derechos humanos.

En tercer lugar, en relación con los sujetos que deben ser investigados, juzgados y sancionados, sigue existiendo incertidumbre en relación con la convencionalidad de los mecanismos de selección de los máximos responsables. Este vacío se debe, en gran parte, a que ha sido una regla reiterada, incluso en casos de justicia transicional, que le corresponde al Estado investigar, juzgar y sancionar a todos los responsables. No obstante, en los casos Masacre de Santodomingo y Yarce y otras contra Colombia, el Tribunal no solo parece aceptar estas modalidades de investigación, sino que en el último caso, instó al Estado a continuar en su implementación.

Por último, en relación con el derecho a la reparación, se observaron dos posturas de la Corte. La primera que buscó proyectar y respaldar los programas de reparación administrativos y la segunda en la que ha retrotraído los avances y ha optado por ser más tímida y prudente, a la hora de remitir a los mecanismos internos. 


\section{Ante la jurisprudencia del futuro}

Sin duda, el caso colombiano, tras la firma del Acuerdo de Paz y el inicio del proceso de implementación, es la prueba ácida para seguir avanzando en la jurisprudencia con respecto a los tres derechos en un contexto de transición de conflicto armado hacia la paz.

La Corte hasta ahora no ha conocido un caso que presente un modelo como el colombiano, que pretende diseñar e implementar una estrategia verdaderamente integral de justicia transicional, en la que los mecanismos judiciales y extrajudiciales se complementan y realimentan.

En consecuencia, los principales desafíos que deberá enfrentar la Corte IDH, en relación con el caso colombiano, serán aclarar y unificar la jurisprudencia relacionada con los siguientes aspectos:

1. El valor jurídico de los acuerdos de paz, especialmente en temas de derechos humanos.

2. Los límites a la participación política de excombatientes.

3. El alcance y convencionalidad de la ley de amnistía y de los principios de selección y priorización (y máximos responsables y probablemente responsabilidad del mando).

4. El alcance de la Ley de Víctimas y del modelo de reparación del Sistema Integral de Verdad, Justicia y Reparación.

Al analizar estos temas, la Corte se enfrentará al gran desafío de revisar cuál es el impacto del modelo en el principio de subsidiariedad, cuál es el margen de apreciación del Estado en torno a estos temas y si tendrá sentido que la Corte siga conociendo casos individuales, reparando individualmente y ordenando reparaciones individuales, de cara a este modelo integral. Mucho dependerá de una adecuada implementación. 


\section{BIBLIOGRAFÍA}

\section{Libros y contribuciones en obras colectivas}

Acosta Juana y Espitia Cindy, El valor del precedente en la Corte Interamericana de Derecho Humanos: vacíos, prácticas y lecciones, en El precedente judicial y el ejercicio del derecho ante las altas cortes, 393-411 (Leonardo López, Universidad de Medellín, Medellín, 2015).

Jáuregui, Gurutz, Derechos individuales versus derechos colectivos. Una realidad inescindible, en Una discusión sobre derechos colectivos, 40-47 (Francisco Ansuátegui, Dykinson S.L., Madrid, 2008).

Londoño María Carmelina, Las garantías de no repetición en la jurisprudencia interamericana: derecho internacional y cambios estructurales del Estado, I, 19-38 (1 Ed., Tirant Lo Blanch, México, 2014).

Mallinder Louise, Amnesty, Human Rights and Political Transitions: Bridging the Peace and Justice Divide, 21, 218-232 (1 Ed., Bloomsbury Publishing, Portland, 2008).

Marchuk Iryna, The Fundamental Concept of Crime in International Criminal Law, 1, 69-113 (Faculty of Law University of Copenhagen Copenhagen, Denmark, 2014).

Uprimny Rodrigo, Justicia para la paz. Crímenes atroces, derecho a la justicia y paz negociada, I, 28-30 (1 Ed., Dejusticia, Bogotá, 2014).

\section{Artículos de revista}

Acosta, Juana, The Inter-American Human Rights System and the Colombian Peace: Redefining the fight against impunity, AJIL Unbound, 1, 178-182 (2016).

Becerra, Manuel, Prevenir, investigar, sancionar y reparar como deberes del Estado frente a las violaciones de derechos humanos, Instituto de investigaciones jurídicas, 1, 134-143 (2013).

Cersale di Cerisano, Federico, Justicia Transicional en las Américas. El impacto del Sistema Interamericano, Revista IIDH, 57, 115-136 (2013).

De Gamboa Tapias, Camila, Justicia transicional: dilemas y remedios para lidiar con el pasado, Estud. Socio-Jurid., 7, 21-40 (2005).

Espinosa, Olger, Acerca del "control de convencionalidad" por parte de los operadores de justicia (nacionales e internacionales) en situaciones de justicia transicional, Revista IIDH, 25, 215-271 (2012).

Fajardo, Luis, Elementos estructurales del derecho a la verdad, Civilizar 12, 15-33 (2012);

Freeman, Michael, Are There Collective Human Rights?, Political Studies 43, 25-40 (1995).

García-Sayán, Diego, Una viva interacción: Corte Interamericana y tribunales internos, La Corte Interamericana de Derechos Humanos, un cuarto de siglo 1, 3-40 (2004).

Gómez, María, La doble dimensión del derecho a la justicia en la justicia transicional de Colombia, Vniversitas 14, 45-52 (2016). 
González, Damián, El derecho a la verdad en situaciones de post-conflicto bélico de carácter no internacional, Int. Law: Rev. Colomb. Derecho Int. 13, 435-467 (2008).

Gutiérrez, Luis, La obligación internacional de investigar, juzgar y sancionar graves violaciones a los derechos humanos en contextos de justicia transicional, Estudios Socio-Jurídicos 16, 23-60 (2014).

Lundy, Patricia \& McGovern, Mark, Whose Justice? Rethinking Transitional Justice from the bottom up, Journal of Law and Society 35, 265-292 (2008).

Naqvi, Yasmin, The Right to the Truth in International Law: Fact or Fiction?, International Review of the Red Cross 88, 245-273 (2006).

Olsen, Tricia; Payne Leigh \& Reiter Andrew, The Justice Balance: When Transitional Justice Improves Human Rights And Democracy, Human Rights Quarterly 32, 980-1007 (2010).

Tomuschat, Christian, Common Values And The Place Of The Charter In Europe, European review of public 12, 14, 159-191 (2002).

\section{Jurisprudencia internacional}

Corte IDH, Caso Barrios Altos vs. Perú. Sentencia del 14 de marzo de 2001. Fondo.

Corte IDH, Caso Almonacid Arellano contra Chile. Sentencia del 26 de septiembre de 2006. Excepciones preliminares, fondo, reparaciones y costas.

Corte IDH, Caso La Cantuta contra Perú. Sentencia del 29 de noviembre de 2006. Fondo, reparaciones y costas.

Corte IDH, Caso Gelman contra Uruguay. Sentencia del 24 de febrero de 2011. Fondo y reparaciones.

Corte IDH, Caso Gomes Lund y otros ("Guerrilha do Araguaia”) contra Brasil. Sentencia del 24 de noviembre de 2010. Excepciones preliminares, fondo, reparaciones y costas.

Corte IDH, Caso Masacres de El Mozote y lugares aledaños contra El Salvador. Sentencia del 25 de octubre de 2012. Fondo, reparaciones y costas.

Corte IDH, Caso Masacre de Santo Domingo contra Colombia. Sentencia del 30 de noviembre de 2012. Excepciones preliminares, fondo y reparaciones.

Corte IDH, Comunidades afrodescendientes desplazadas de la cuenca del río Cacarica (Operación Génesis) contra Colombia. Sentencia del 20 de noviembre de 2013. Excepciones preliminares, fondo, reparaciones y costas.

Corte IDH, Caso Rochac Hernández contra El Salvador. Sentencia del 14 de octubre de 2014. Fondo, reparaciones y costas.

Corte IDH, Caso Rodríguez Vera y otros (Desaparecidos del Palacio de Justicia) contra Colombia. Sentencia del 14 de noviembre de 2014. Excepciones preliminares, fondo, reparaciones y costas.

Corte IDH, Caso Tenorio Roca y otros contra Perú. Sentencia del 22 de junio de 2016. Excepciones preliminares, fondo, reparaciones y costas.

Corte IDH, Caso Yarce y otras contra Colombia. Sentencia del 22 de noviembre de 
2016. Excepción preliminar, fondo, reparaciones y costas.

Corte IDH, Caso Miembros de la aldea Chichupac y comunidades vecinas del municipio de Rabinal contra. Guatemala. Sentencia del 30 de noviembre de 2016. Excepciones preliminares, fondo, reparaciones y costas.

Voto concurrente del juez Diego García-Sayán. Sentencia de la Corte IDH, Caso Masacres de El Mozote y lugares aledaños contra. El Salvador. 25 de octubre de 2012.

\section{Normatividad y jurisprudencia nacional}

Acuerdo final para la terminación del conflicto y la construcción de una paz estable y duradera. 24 de noviembre de 2016. Punto 5. Sistema Integral de Verdad, Justicia, Reparación y No Repetición.

Corte Constitucional de la República de Colombia, Sala Plena, Sentencia C-694 de 2015, 11 de noviembre de 2015, Expediente D-9818. Magistrado ponente: Alberto Rojas Ríos.

Corte Constitucional de la República de Colombia, Sala Plena, Sentencia C-579 de 2013. 28 de agosto de 2013, Expediente D-9499. Magistrado sustanciador: Jorge Ignacio Pretelt Chaljub. 